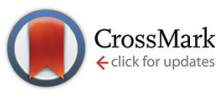

Cite this: Food Funct., 2016, 7, 3083

\title{
Artichoke and milk thistle pills and syrups as sources of phenolic compounds with antimicrobial activity
}

\author{
Carla Pereira, ${ }^{a}$ Lillian Barros, ${ }^{* a, b}$ Maria José Alves, ${ }^{c}$ Celestino Santos-Buelga ${ }^{\mathrm{d}}$ and \\ Isabel C. F. R. Ferreira ${ }^{\star a}$
}

\begin{abstract}
Dietary supplements based on hepatoprotective plants have been increasingly used in the prevention of liver injuries. In the present work, the aim was to study the phenolic profile and possibly relate it to the in vitro antimicrobial activity of two different formulations (pills and syrups) of artichoke and milk thistle, the antioxidant and anti-hepatocellular carcinoma activities of which were previously reported by our research group. The phenolic profiles were obtained by HPLC-DAD-ESI/MS, and the antimicrobial activity evaluation was performed with the clinical isolates of multiresistant bacteria (Escherichia coli, extended spectrum $\beta$-lactamases (ESBL) producing Escherichia coli, Proteus mirabilis, methicillin-resistant Staphylococcus aureus (MRSA) and Pseudomonas aeruginosa). Artichoke syrup revealed the presence of vanillic acid and luteolin-7-O-glucoside while the pills possessed higher concentrations of 4-O-caffeoylquinic, 5-O-caffeoylquinic and 1,3-O-dicaffeoylquinic acids, this latest being able to inhibit the growth of MRSA. Regarding milk thistle formulations, the syrup presented isorhamnetin- $O$-deoxyhexoside- $O$-dihexoside, isorhamnetin-O-deoxyhexoside-O-hexoside and isorhamnetin-3-O-rutinoside as the major phenolic constituents whereas the pills were richer in taxifolin, silymarin derivatives and hydroxylated silibinin; the syrup revealed antimicrobial activity against all the studied bacteria with the exception of Proteus mirabilis whereas the pills revealed activity against ESBL producing Escherichia coli. Overall, all of the studied formulations revealed to be a good source of phenolic compounds, among which milk thistle syrup presented the highest variety and concentration of flavonoids, which is possibly related to its strongest antimicrobial activity.
\end{abstract}

Received 11th April 2016 Accepted 20th May 2016

DOI: $10.1039 / \mathrm{c} 6 f \circ 00512 \mathrm{~h}$

www.rsc.org/foodfunction which artichoke (Cynara scolymus L.) and milk thistle (Silybum marianum (L.) Gaertn) are two herbs with several therapeutic applications and are also described as good sources of flavonoids and phenolic acids. ${ }^{4,5}$ In previous studies, extracts from these plants and their isolated phenolic compounds proved to be able to inhibit the growth of several bacterial strains, which led some authors to conclude that their antimicrobial capacity can be attributed to their phenolic composition. For instance, the hydroalcoholic extracts of artichoke leaves showed activity against Escherichia coli and Salmonella abony enterica, ${ }^{6}$ and phenolic extracts from its hearts and bracts against Escherichia coli, Pseudomonas aeruginosa, Staphylococcus aureus, Bacillus subtilis, Aspergillus niger and Candida albicans. ${ }^{7}$ On the other hand, milk thistle seed extracts were effective against Escherichia coli, Staphylococcus sprophyticus, Staphylococcus aureus, and Klebsiella pneumoniae, ${ }^{8}$ while silymarin and silibinin, characteristic phenolic compounds of milk thistle, inhibited Escherichia coli, Pseudomonas aeruginosa, and Staphylococcus aureus. ${ }^{9}$

Nowadays, with the tremendous development of the dietary supplements industry, herbal formulations based on these and many other medicinal plants are available in various formulations such as dry material for infusion preparation, pills, capsules, syrups, lotions, ampoules, etc. ${ }^{10}$ Nevertheless, scarce 
studies have been conducted in order to clarify the differences between the phenolic composition and bioactivity of such formulations, and in this framework, the present study aimed to provide complementary scientific information regarding dietary supplements (pills and syrups) based on artichoke and milk thistle that previously proved to possess antioxidant and anti-hepatocellular carcinoma activities. ${ }^{11,12}$ For this purpose, phenolic characterization was performed by HPLC-DAD-ESI/ MS, and the in vitro antimicrobial activity evaluation was performed against the clinical isolates of multiresistant bacteria (Escherichia coli, extended spectrum $\beta$-lactamases (ESBL) producing Escherichia coli, Proteus mirabilis, methicillin-resistant Staphylococcus aureus (MRSA) and Pseudomonas aeruginosa) obtained from the Hospital Center of Trás-os-Montes and Alto Douro (CHTMAD, Chaves, Portugal).

\section{Materials and methods}

\subsection{Samples}

Cynara scolymus L. (artichoke) and Silybum marianum (L.) Gaertn (milk thistle) were obtained from an herbalist shop in Bragança (Portugal), as pills and syrups. According to the label information, the pills contain an agglutinative (modified corn starch), a diluent (microcrystalline cellulose), an anti-agglomeration agent (dibasic calcium phosphate anhydrous and silicon dioxide), a lubricant (magnesium stearate), and $500 \mathrm{mg}$ of artichoke or milk thistle plant dry extract, for each case. The syrups are composed of $100 \%$ of artichoke, water and preservative (methyl $p$-hydroxybenzoate); and $2.3 \%$ of milk thistle, sea buckthorn, carriers (fructose, water), sweetener (sorbitol), thickening agents (guar and locust bean gum), preservative (potassium sorbate), acidifier (L-ascorbic acid), and stabilizer (pectin).

\subsection{Standards and reagents}

HPLC-grade acetonitrile was obtained from Merck KgaA (Darmstadt, Germany). Formic acid was purchased from Prolabo (VWR International, Fontenay-sous-Bois, France). Phenolic standards were from Extrasynthèse (Genay, France). Water was treated using a Milli-Q water purification system (TGI Pure Water Systems, Greenville, SC, USA). Methanol was of analytical grade purity from Lab-Scan (Lisbon, Portugal). The culture media Mueller Hinton Broth (MHB), WilkinsChalgren broth (WCB) and Columbia agar (CA) with 5\% horse blood were obtained from Biomerieux (Marcy l'Etoile, France). The dye $p$-iodonitrotetrazolium chloride (INT) was purchased from Sigma-Aldrich (St Louis, MO, USA) to be used as a microbial growth indicator.

\subsection{Characterization in phenolic compounds}

2.3.1. Extraction procedures. The pills (1.5 g) were ground to powder and subjected to hydromethanolic extraction by stirring with $25 \mathrm{~mL}$ of methanol : water $\left(80: 20 \mathrm{v} / \mathrm{v}, 25{ }^{\circ} \mathrm{C}\right.$ at 150 $\mathrm{rpm}$ ) for $1 \mathrm{~h}$ and subsequently filtered through Whatman no. 4 paper. The residues were then extracted with an additional $25 \mathrm{~mL}$ of methanol : water $(80: 20 \mathrm{v} / \mathrm{v})$ for another hour. The combined extracts were dried (Büchi R-210, Flawil, Switzerland) and purified using a $\mathrm{C}_{18}$ SepPak ${ }^{\circledR}$ Vac 3 cc cartridge (Phenomenex), previously activated with methanol followed by water; sugars and more polar substances were removed by passing $10 \mathrm{~mL}$ of water through the cartridge and the purified samples were further eluted with $5 \mathrm{~mL}$ of methanol. The extracts were concentrated under vacuum.

The artichoke syrup ( $5 \mathrm{~mL}$ ) was subjected to purification following the procedure described above and then concentrated under vacuum. Regarding the milk thistle syrup, due to its consistency, it was extracted and purified following the procedure described for the pills, the obtained extract was then concentrated under vacuum.

2.3.2. Analysis of phenolic compounds. The previously described extracts were dissolved in water: methanol $(80: 20$, $\mathrm{v} / \mathrm{v}$ ) to the final concentrations of 3 and $59 \mathrm{mg} \mathrm{mL}^{-1}$ for the pills and 7 and $16 \mathrm{mg} \mathrm{mL} \mathrm{m}^{-1}$ for the syrups of artichoke and milk thistle, respectively. The analysis was performed using a Hewlett-Packard 1100 chromatograph (Hewlett-Packard 1100, Agilent Technologies, Santa Clara, CA, USA) with a quaternary pump and a diode array detector (DAD) coupled to an HP Chem Station (rev. A.05.04) data-processing station. A Waters Spherisorb S3 ODS-2 $\mathrm{C}_{18}, 3 \mu \mathrm{m}(4.6 \mathrm{~mm} \times 150 \mathrm{~mm})$ column thermostatted at $35{ }^{\circ} \mathrm{C}$ was used. The solvents were (A) $0.1 \%$ formic acid in water, and (B) acetonitrile. The elution gradient established was isocratic $15 \%$ for $5 \mathrm{~min}, 15 \% \mathrm{~B}$ to $20 \%$ B over $5 \mathrm{~min}, 20-25 \%$ B over $10 \mathrm{~min}, 25-35 \%$ B over $10 \mathrm{~min}, 35-50 \%$ for $10 \mathrm{~min}$, and re-equilibration of the column, using a flow

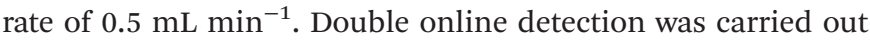
in the DAD using $280 \mathrm{~nm}$ and $370 \mathrm{~nm}$ as the preferred wavelengths and in a mass spectrometer (MS) connected to the HPLC system via the DAD cell outlet.

MS detection was performed using an API 3200 Qtrap (Applied Biosystems, Darmstadt, Germany) equipped with an ESI source and a triple quadrupole-ion trap mass analyzer that was controlled by using the Analyst 5.1 software. Zero grade air served as the nebulizer gas (30 psi) and turbo gas for solvent drying (400 $\left.{ }^{\circ} \mathrm{C}, 40 \mathrm{psi}\right)$. Nitrogen served as the curtain (20 psi) and collision gas (medium). The quadrupoles were set at unit resolution. The ion spray voltage was set at $-4500 \mathrm{~V}$ in the negative mode. The MS detector was programmed for recording in two consecutive modes: enhanced MS (EMS) and enhanced product ion (EPI) analysis. EMS was employed to record full scan spectra, so as to obtain an overview of all of the ions in the sample. The settings used were: declustering potential (DP) $-450 \mathrm{~V}$, entrance potential (EP) $-6 \mathrm{~V}$, and collision energy (CE) $-10 \mathrm{~V}$. The EPI mode was performed in order to obtain the fragmentation pattern of the parent ion(s) in the previous scan using the following parameters: DP $-50 \mathrm{~V}, \mathrm{EP}-6 \mathrm{~V}, \mathrm{CE}-25 \mathrm{~V}$, and collision energy spread (CES) $0 \mathrm{~V}$. Spectra were recorded in negative ion mode between $\mathrm{m} / \mathrm{z} 100$ and 1500 .

The phenolic compounds were identified by comparing their retention time, UV-vis and mass spectra with those obtained from standard compounds, when available. Otherwise, compounds were tentatively identified by comparing the obtained information with the available data reported in the 
literature. For quantitative analysis, a calibration curve for each available phenolic standard was constructed based on the UV signal. For the identified phenolic compounds for which a commercial standard was not available, the quantification was performed using the calibration curve of other compounds from the same phenolic group. The results were expressed in $\mu \mathrm{g}$ per $\mathrm{g}$ of lyophilized extract. For each formulation, the analyses were carried out in triplicate.

\subsection{Evaluation of antimicrobial activity}

2.4.1. Sample preparation. The pills were ground to powder and dissolved in distilled water to a final concentration of $150 \mathrm{mg} \mathrm{mL}^{-1}$. The syrups were directly used in the concentrations of 1000 and $26 \mathrm{mg} \mathrm{mL} \mathrm{m}^{-1}$, according to the label information.

2.4.2. Antimicrobial activity assays. To screen the antimicrobial activity, the used microorganisms were clinical isolates from patients hospitalized in various departments of the Hospital Center of Trás-os-Montes and Alto Douro (Vila Real, Portugal). Four Gram-negative bacteria (Escherichia coli isolated from urine, extended spectrum $\beta$-lactamases (ESBL) producing Escherichia coli isolated from blood culture, Proteus mirabilis isolated from wound exudates and Pseudomonas aeruginosa isolated from urine) and one Gram-positive bacterium (methicillin-resistant Staphylococcus aureus (MRSA) isolated from wound exudates) were used. Microorganism's identification and susceptibility tests were performed using MicroScan panels (MicroScan ${ }^{\circledR}$; Siemens Medical Solutions Diagnostic, West Sacramento, CA, USA) by the microdilution plate method. The interpretation criteria were based on interpretative breakpoints as indicated in EUCAST (European Committee on Antimicrobial Susceptibility Testing) ${ }^{13}$ and Clinical and Laboratory Standards Institute (CLSI) document M100-
$\mathrm{S}_{1} 8^{14}$ and the report of the Committee of L'Antibiogramme de la Société Française de Microbiologie (CA-SFM). ${ }^{15}$

Minimum inhibitory concentration (MIC) determinations were performed by the microdilution method and the rapid $p$-iodonitrotetrazolium chloride (INT) colorimetric assay following the methodology previously described by Alves et al. ${ }^{16}$

Initially, $50 \mu \mathrm{L}$ of each extract was diluted in $450 \mu \mathrm{L}$ of $\mathrm{MHB}$ (final concentration of $15 \mathrm{mg} \mathrm{mL}{ }^{-1}$ for the pills; 100 and $2.6 \mathrm{mg} \mathrm{mL}^{-1}$ for the syrups of artichoke and milk thistle, respectively) and then, $200 \mu \mathrm{L}$ of this extract solution was added in each well (96-well microplate). Dilutions were carried out over the wells with $100 \mu \mathrm{L}$ of MHB and, afterwards, $10 \mu \mathrm{L}$ of inoculum $(1.5 \times$

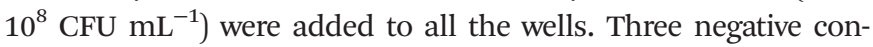
trols were prepared with MHB, extract, bacterium and antibiotics. Tobramycin and vancomycin were used for Gram negative and positive bacteria, respectively, at concentrations according to the obtained MIC values (Tables 1 and 2). A positive control was also prepared with $\mathrm{MHB}$ and the inoculum. The plates were incubated at $37^{\circ} \mathrm{C}$, for $24 \mathrm{~h}$, in an oven (Jouan).

The MICs of the samples were determined after adding $40 \mu \mathrm{L}$ of INT $\left(0.2 \mathrm{mg} \mathrm{mL} \mathrm{m}^{-1}\right)$ and incubating at $37{ }^{\circ} \mathrm{C}$ for $30 \mathrm{~min}$. Viable microorganisms reduced the yellow dye to a pink color. MIC was defined as the lowest extract concentration that prevented this change and exhibited inhibition of bacterial growth. All the assays were carried out in duplicate.

\section{Results and discussion}

\subsection{Phenolic compounds}

Tables 3 and 4 present the data obtained from HPLC-DAD-MS analysis (retention time, $\lambda_{\max }$ in the visible region, mass spec-

Table 1 MIC values ( $\mu \mathrm{g} \mathrm{ml}^{-1}$ ) of different antibiotics against Gram negative bacteria

\begin{tabular}{|c|c|c|c|c|c|c|c|c|}
\hline \multirow[b]{2}{*}{ Ampicillin } & \multicolumn{2}{|l|}{ E. coli } & \multicolumn{2}{|c|}{$\begin{array}{l}\text { ESBL producing } \\
\text { E. coli }\end{array}$} & \multicolumn{2}{|c|}{ P. mirabilis } & \multicolumn{2}{|c|}{ P. Aeruginosa } \\
\hline & $>16$ & $\mathrm{R}$ & $\geq 32$ & $\mathrm{R}$ & $\leq 8$ & $\mathrm{~S}$ & & $\mathrm{Na}$ \\
\hline Amoxicillin/clavulanic acid & $16 / 8$ & $\mathrm{R}$ & $\geq 16 / 8$ & $\mathrm{R}$ & $\leq 8 / 4$ & $\mathrm{~S}$ & & $\mathrm{Na}$ \\
\hline Cephalothin & 8 & $\mathrm{~S}$ & $\geq 64$ & $\mathrm{R}$ & $\leq 8$ & $S$ & & $\mathrm{Na}$ \\
\hline Cefazolin & $\leq 8$ & $\mathrm{~S}$ & & na & $\leq 8$ & $S$ & & $\mathrm{Na}$ \\
\hline Cefuroxime & $\leq 4$ & $\mathrm{~S}$ & $\geq 64$ & $\mathrm{R}$ & $\leq 4$ & $\mathrm{~S}$ & & $\mathrm{Na}$ \\
\hline Cefoxitin & $\leq 8$ & $\mathrm{~S}$ & & na & $\leq 8$ & $\mathrm{~S}$ & & na \\
\hline Cefotaxime & $\leq 1$ & $\mathrm{~S}$ & $\geq 64$ & $\mathrm{R}$ & $\leq 1$ & $\mathrm{~S}$ & 16 & $\mathrm{R}$ \\
\hline Ceftazidime & $\leq 1$ & $\mathrm{~S}$ & 4 & $\mathrm{I}$ & $\leq 1$ & $\mathrm{~S}$ & 2 & $\mathrm{~S}$ \\
\hline Cefepime & 16 & $\mathrm{~S}$ & & na & $\leq 1$ & $\mathrm{~S}$ & 4 & $\mathrm{~S}$ \\
\hline Nalidíxic acid & $>16$ & $\mathrm{R}$ & na & $>16$ & $\mathrm{R}$ & & & na \\
\hline Norfloxacin & $>8$ & $\mathrm{R}$ & & na & 4 & $\mathrm{~S}$ & & na \\
\hline Ciprofloxacin & $>2$ & $\mathrm{R}$ & $\geq 4$ & $\mathrm{R}$ & $>2$ & $\mathrm{R}$ & $\leq 0.5$ & $\mathrm{~S}$ \\
\hline Nitrofurantoin & $\leq 32$ & $\mathrm{~S}$ & 64 & $\mathrm{~S}$ & $>64$ & $\mathrm{R}$ & & na \\
\hline Fosfomycin & $\leq 16$ & $\mathrm{~S}$ & & na & $>64$ & $\mathrm{R}$ & & na \\
\hline Gentamicin & $\leq 2$ & $\mathrm{~S}$ & $\leq 1$ & $\mathrm{~S}$ & 8 & I & $>8$ & $\mathrm{R}$ \\
\hline Imipenem & $\leq 1$ & $\mathrm{~S}$ & & na & 2 & $\mathrm{~S}$ & $\leq 1$ & $\mathrm{~S}$ \\
\hline Piperacilin/Tazobactam & $\leq 8$ & $\mathrm{~S}$ & $\leq 4$ & $\mathrm{~S}$ & $\leq 8$ & $\mathrm{~S}$ & $\leq 8$ & $\mathrm{~S}$ \\
\hline Trimethoprim/Sulfasoxazole & $\leq 2 / 38$ & $\mathrm{~S}$ & $\geq 320$ & $\mathrm{R}$ & $>4 / 76$ & $\mathrm{R}$ & $4 / 76$ & $\mathrm{R}$ \\
\hline Tobramycin & $\leq 2$ & $\mathrm{~S}$ & $\leq 1$ & $\mathrm{~S}$ & 4 & $\mathrm{~S}$ & 4 & $\mathrm{~S}$ \\
\hline
\end{tabular}

$\mathrm{S}$ - susceptible; I - intermediate; R - resistant (this classification was made according to the interpretative breakpoints suggested by the Clinical and Laboratory Standards Institute - CLSI and European Committee on Antimicrobial Susceptibility Testing (EUCAST)); na - not applicable. 
Table 2 MIC values $\left(\mu \mathrm{g} \mathrm{ml}^{-1}\right)$ of different antibiotics against Gram positive bacteria

\begin{tabular}{llllll}
\hline MRSA & \multicolumn{5}{c}{ MRSA } \\
\hline Penicillin & $>8$ & Blac & Ciprofloxacin & $>2$ & R \\
Ampicillin & $>8$ & Blac & Levofloxacin & $>4$ & R \\
Cefoxitin Screen & $>4$ & Pos & Linezolid & 2 & S \\
Oxacillin & $>2$ & R & Synercid & 1 & S \\
Clindamycin & 1 & I & Teicoplanin & 2 & S \\
Daptomycin & $\leq 0.5$ & S & Tetracycline & $\leq 1$ & S \\
Erythromycin & $\leq 0.25$ & S & Trimethoprim/ & $\leq 1 / 19$ & S \\
& & & Sulfasoxazole & & \\
Fosfomycin & $\leq 32$ & S & Vancomycin & 2 & S \\
Gentamicin & 4 & S & & &
\end{tabular}

S - susceptible; I - intermediate; R - resistant (this classification was made according to the interpretative breakpoints suggested by the Clinical and Laboratory Standards Institute - CLSI and European Committee on Antimicrobial Susceptibility Testing (EUCAST)); Blac Beta-lactamase positive; Pos - positive to cefoxitin screening; Neg negative to cefoxitin screening; na - not applicable.

tral data) used for the identification and quantification of phenolic compounds in artichoke and milk thistle formulations.

The phenolic compounds identified in artichoke formulations obviously showed similarities to the infusions and hydroalcoholic extracts previously analysed by our research group ${ }^{5}$ all the detected compounds being already described and tentatively identified, with the exception of peaks $2^{\mathrm{A}}, 8^{\mathrm{A}}$ and $16^{\mathrm{A}}$. Compound $2^{\mathrm{A}}$ was positively identified as vanillic acid, according to its retention time, mass and UV-vis characteristics by comparison with a commercial standard. To the best of our knowledge, vanillic acid has not been described in artichoke, thus it might be present in the syrup due to its addition as a flavouring agent, even though it was not mentioned on the label. Compounds $8^{\mathrm{A}}$ and $16^{\mathrm{A}}$ were tentatively identified as 4-O-caffeoylquinic acid and 3,4-O-dicaffeoylquinic acid, respectively, taking into account the fragmentation patterns reported by Clifford et al. ${ }^{17,18}$ and previous identifications in other materials in our laboratory. ${ }^{19-21}$

Different monocaffeoylquinic and dicaffeoylquinic acids in different parts of artichoke have been widely reported by many authors. ${ }^{22-31}$ The syrup did not contain this type of compound, but showed apigenin and luteolin derivatives, which are also very characteristic of artichoke (with the exception of vanillic acid), with luteolin-7-O-glucoside being the most abundant compound. The main compounds present in the pills were chlorogenic acid (i.e., 5-O-caffeoylquinic acid) and cynarin (i.e., 1,3-O-dicaffeoylquinic acid); these molecules are also the most characteristic compounds found in artichoke. The absence of cynarin in the syrup (Table 3) could be explained by its dependence on the part of the plant used (information not provided on

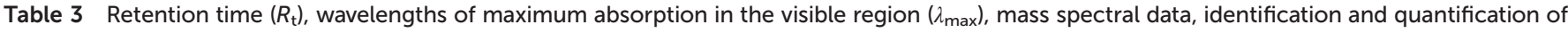
phenolic compounds in syrup and pill formulations of artichoke (mean \pm SD)

\begin{tabular}{|c|c|c|c|c|c|c|}
\hline Compound & $\begin{array}{l}R_{\mathrm{t}} \\
(\mathrm{min})\end{array}$ & $\begin{array}{l}\lambda_{\max } \\
(\mathrm{nm})\end{array}$ & $\begin{array}{l}\text { Molecular ion } \\
{[\mathrm{M}-\mathrm{H}]^{-}(\mathrm{m} / \mathrm{z})}\end{array}$ & $\operatorname{MS}^{2}(m / z)$ & Tentative identification & $\begin{array}{l}\text { Quantification } \\
\left(\mu g g^{-1}\right)\end{array}$ \\
\hline \multicolumn{7}{|l|}{ Syrup } \\
\hline $1^{\mathrm{A}-\mathrm{T}}$ & 14.1 & 338 & 607 & $269(100)$ & Apigenin-O-hexoside- $O$-glucuronide & $0.29 \pm 0.01$ \\
\hline $2^{\mathrm{A}}$ & 15.5 & $264,296 \mathrm{sh}$ & 167 & $123(100)$ & Vanillic acid & $5.58 \pm 0.02$ \\
\hline $3^{\mathrm{A}}$ & 19.7 & 350 & 461 & $285(100)$ & Luteolin-7-O-glucoronide & $0.72 \pm 0.04$ \\
\hline $4^{\mathrm{A}}$ & 20.6 & 354 & 447 & $285(100)$ & Luteolin-7-O-glucoside & $2.2 \pm 0.1$ \\
\hline $5^{\mathrm{A}}$ & 25.1 & 336 & 431 & $269(100)$ & Apigenin-7-O-glucoside & $0.49 \pm 0.02$ \\
\hline & & & & & Total phenolic acids & $5.58 \pm 0.02$ \\
\hline & & & & & Total flavonoids & $3.7 \pm 0.1$ \\
\hline & & & & & Total phenolic compounds & $9.3 \pm 0.1$ \\
\hline \multicolumn{7}{|c|}{ 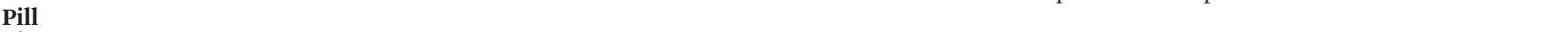 } \\
\hline $6^{\mathrm{A}}$ & 5.2 & 326 & 353 & 191(100), 179(82), 135(73) & 3-O-Caffeoylquinic acid & $1.854 \pm 0.005$ \\
\hline $7^{\mathrm{A}}$ & 5.6 & 324 & 341 & $179(85), 135(100)$ & Caffeic acid hexoside & $2.0 \pm 0.1$ \\
\hline $8^{\mathrm{A}}$ & 7.2 & 328 & 353 & $\begin{array}{l}\text { 191(59), 179(64), 173(100), } \\
\text { 161(10), 135(77) }\end{array}$ & 4-O-Caffeoylquinic acid & $13.3 \pm 0.3$ \\
\hline $9^{\mathrm{A}}$ & 7.9 & 328 & 353 & $\begin{array}{l}\text { 191(100), 179(32), 173(20), } \\
161(6), 135(12)\end{array}$ & 5-O-Caffeoylquinic acid & $28.2 \pm 0.7$ \\
\hline $10^{\mathrm{A}}$ & 11.4 & 324 & 179 & $135(100)$ & Caffeic acid & $1.7 \pm 0.2$ \\
\hline $11^{\mathrm{A}}$ & 12.4 & 324 & 515 & $\begin{array}{l}353(85), 335(11), 191(100), \\
179(90), 173(6), 161(12), 135(49)\end{array}$ & 1,3-O-Dicaffeoylquinic acid & $24 \pm 1$ \\
\hline $1^{\mathrm{A}}$ & 14.5 & 334 & 607 & $431(43), 269(43)$ & Apigenin-O-hexoside- $O$-glucuronide & $1.36 \pm 0.06$ \\
\hline $13^{\mathrm{A}}$ & 17.1 & 312 & 163 & $119(100)$ & $p$-Coumaric acid & $0.041 \pm 0.009$ \\
\hline $14^{\mathrm{A}}$ & 19.6 & 350 & 593 & $285(100)$ & Luteolin-7-O-rutinoside & $1.37 \pm 0.07$ \\
\hline $3^{\mathrm{A}}$ & 20.3 & 348 & 461 & $285(100)$ & Luteolin-7-O-glucuronide & $2.59 \pm 0.08$ \\
\hline $16^{\mathrm{A}}$ & 20.7 & 326 & 515 & $\begin{array}{l}353(49), 335(17), 191(47), 179(58), \\
173(83), 161(22), 135(46)\end{array}$ & 3,4-O-Dicaffeoylquinic acid & $6.1 \pm 0.1$ \\
\hline $17^{\mathrm{A}}$ & 22.7 & 326 & 515 & $\begin{array}{l}353(31), 335(10), 191(100) \\
179(20), 161(8), 135(5)\end{array}$ & 3,5-O-Dicaffeoylquinic acid & $7.1 \pm 0.1$ \\
\hline $5^{\mathrm{A}}$ & 25.0 & 332 & 445 & $269(100)$ & $\begin{array}{l}\text { Apigenin-7-O-glucuronide } \\
\text { Total phenolic acids } \\
\text { Total flavonoids } \\
\text { Total phenolic compounds }\end{array}$ & $\begin{aligned} 3.07 & \pm 0.05 \\
85 & \pm 3 \\
8.4 & \pm 0.3 \\
93 & \pm 2\end{aligned}$ \\
\hline
\end{tabular}


Table 4 Retention time $\left(R_{\mathrm{t}}\right)$, wavelengths of maximum absorption in the visible region $\left(\lambda_{\max }\right)$, mass spectral data, identification and quantification of phenolic compounds in syrup and pill formulations of milk thistle (mean \pm SD)

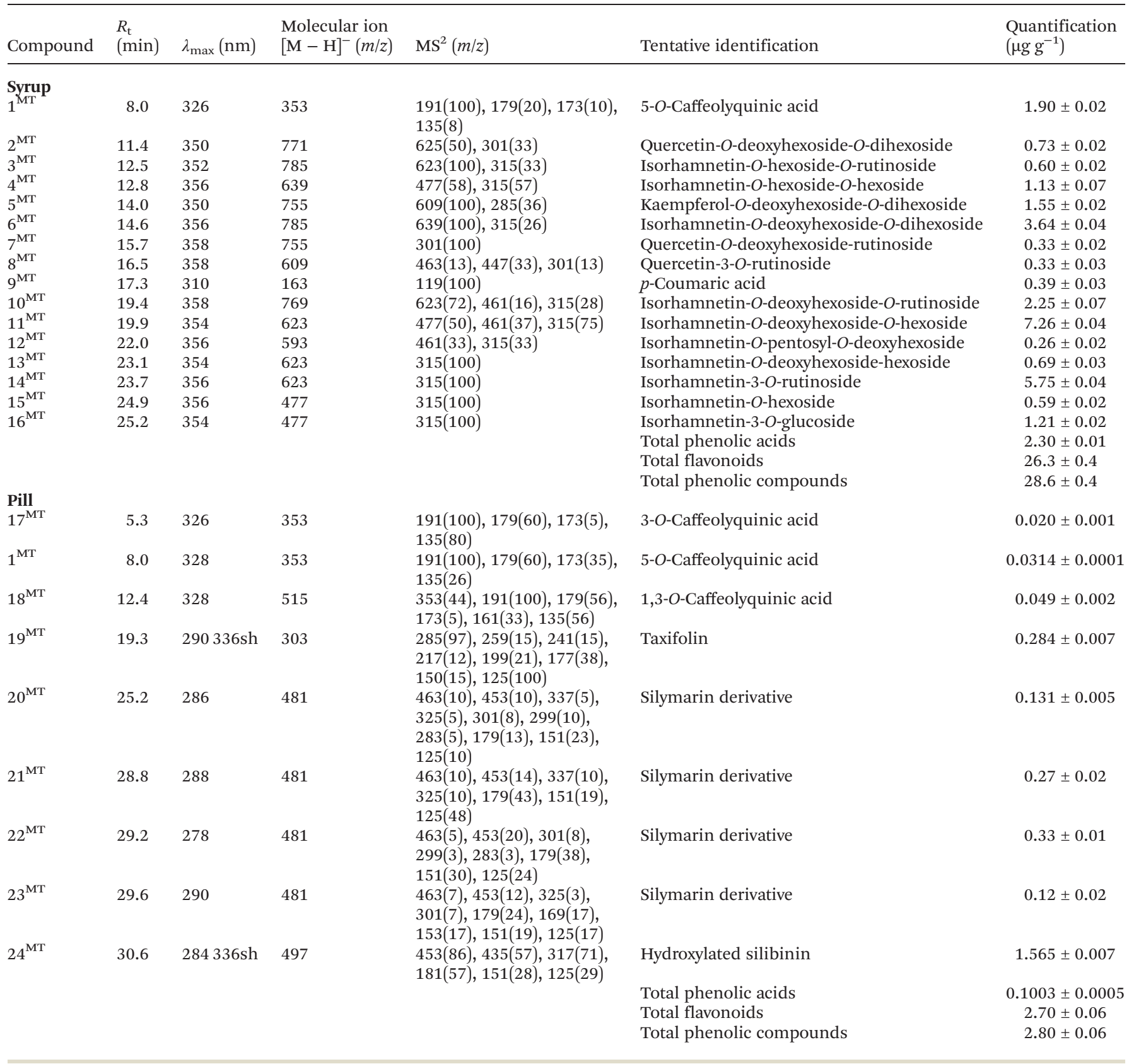

the label), with some studies reporting that artichoke heads have lower contents of cynarin than the leaves or floral stems. ${ }^{25,32}$

In contrast to artichoke, both the formulations of milk thistle hardly presented similarities to the infusions and hydroalcoholic extract previously described, ${ }^{5}$ with the exception of compounds $1^{\mathrm{MT}}$ (5-O-caffeolyquinic acid) and $17^{\mathrm{MT}}$ (3-O-caffeolyquinic acid), that were both identified. ${ }^{5}$ In the literature, milk thistle phenolic composition is characterized by the presence of a mixture of flavonolignans (silymarin), which are known to be normally present in its seeds. ${ }^{33-43}$ Nevertheless, the syrup formulation presented flavonol derivatives, mainly isorhamnetin, quercetin and kaempferol glycoside derivatives, as the main compounds, with the exception of compound $9^{\mathrm{MT}}$, that was positively identified as $p$-coumaric acid, according to its retention time, mass and UV-vis characteristics by comparison with commercial standards, and compound $1^{\mathrm{MT}}(5-\mathrm{O}-$ caffeolyquinic acid).

Compounds $3^{\mathrm{MT}}, 4^{\mathrm{MT}}, 6^{\mathrm{MT}}, 10^{\mathrm{MT}}, 11^{\mathrm{MT}}, 12^{\mathrm{MT}}, 13^{\mathrm{MT}}, 14^{\mathrm{MT}}, 15^{\mathrm{MT}}$ and $16^{\mathrm{MT}}$ were identified as isorhamnetin derivatives owing to the product ion observed at $m / z 315$ and the UV spectra $\left(\lambda_{\max }\right.$ around $352-358 \mathrm{~nm}$ ). Compounds $14^{\mathbf{M T}}$ (isorhamnetin-3-Orutinoside) and $16^{\mathbf{M T}}$ (isorhamnetin-3-O-glucoside) were positively identified by comparison with commercial standards. Peaks $3^{\mathrm{MT}}$ and $6^{\mathrm{MT}}$ presented the same pseudomolecular ion 
$[\mathrm{M}-\mathrm{H}]^{-}$at $m / z 785$, but revealed a different $\mathrm{MS}^{2}$ fragmentation pattern. Compound $3^{\mathrm{MT}}$ presented the consecutive losses of hexosyl (product ion at $\mathrm{m} / \mathrm{z} 623 ;-162 \mathrm{u}$ ) and deoxyhexosylhexoside (ion at $\mathrm{m} / \mathrm{z} 315 ;-308 \mathrm{u}$ ), while peak $6^{\mathrm{MT}}$ presented the losses of deoxyhexosyl $(\mathrm{m} / \mathrm{z}$ at $639 ;-146 \mathrm{u})$ and dihexosyl $(\mathrm{m} / \mathrm{z}$ at $315 ;-324 \mathrm{u})$. For both the peaks, no information about the identity of the sugar moieties and their location in the aglycone could be obtained, so these compounds were tentatively identified as isorhamnetin- $O$-hexoside- $O$-(deoxyhexosylhexoside) and isorhamnetin- $O$-deoxyhexoside- $O$-dihexoside, respectively. Moreover, the positive identification of different rutinosides, including isorhamnetin-3-O-rutinoside, in the analyzed sample may suggest a rutinose identity for the deoxyhexosyl-hexose residue present in peak $3^{\mathrm{MT}}$. Similarly, peak $10^{\mathrm{MT}}$ $\left([\mathrm{M}-\mathrm{H}]^{-}\right.$at $\left.m / z 769\right)$ was assigned to isorhamnetin-O-deoxyhexoside- $O$-rutinoside. The mass characteristics of compound $4^{\mathrm{MT}}\left([\mathrm{M}-\mathrm{H}]^{-}\right.$at $\mathrm{m} / z$ 639) indicated that it corresponds to an isorhamnetin derivative bearing two hexosyl residues. The observation of $\mathrm{MS}^{2}$ fragments at $\mathrm{m} / \mathrm{z} 477(-162 \mathrm{u})$ and 315 $(-162 \mathrm{u})$, also indicated the consecutive loss of each of the hexosyl moieties, pointing to their location on different positions of the aglycone. Thus, this compound was tentatively identified as isorhamnetin- $O$-hexosyl- $O$-hexoside. Moreover, peaks $11^{\mathrm{MT}}$ and $13^{\mathrm{MT}}$ presented the same pseudomolecular ion as compound $14^{\mathrm{MT}}$ (isorhamnetin-3-O-rutinoside), indicating that they should correspond to other isorhamnetin derivatives bearing deoxyhexosyl and hexosyl residues. Nevertheless, the fragmentation pattern of compound $11^{\mathrm{MT}}$, with the alternative losses of the deoxyhexosyl (ion at $m / z$ 477) and hexosyl (ion at $m / z 461$ ) moieties indicated that the sugars were located on different positions of the aglycone, whereas in compound $13^{\mathrm{MT}}$, for which only one ion at $\mathrm{m} / \mathrm{z} 315$ corresponding to the aglycone was produced, the two sugars residues should constitute a disaccharide. Thus, these compounds were tentatively assigned as isorhamnetin-O-deoxyhexosyl-O-hexoside (peak $11^{\mathrm{MT}}$ ) and isorhamnetin- $O$-deoxyhexosyl-hexoside (peak $13^{\mathrm{MT}}$ ). This later could correspond to an isorhamnetin $O$-neohesperidoside or to an $O$-rutinoside bearing the sugar residue on a location different to peak $14^{\mathrm{MT}}$ (isorhamnetin-3-O-rutinoside). Following a similar reasoning, peak $12^{\mathrm{MT}}\left([\mathrm{M}-\mathrm{H}]^{-}\right.$at $\left.m / z 593\right)$ was assigned to isorhamnetin- $O$-pentosyl- $O$-deoxyhexoside, and peak $15^{\mathrm{MT}}\left([\mathrm{M}-\mathrm{H}]^{-}\right.$at $\left.m / z 477\right)$ to an isorhamnetin- $O$ hexoside differing from peak $15^{\mathrm{MT}}$ (isorhamnetin-3-O-glucoside) in the type of sugar or the position of substitution.

Peaks $2^{\mathrm{MT}}, 7^{\mathrm{MT}}$ and $8^{\mathrm{MT}}$ were identified as quercetin glycosides based on their UV spectra ( $\lambda_{\max }$ around $358 \mathrm{~nm}$ ) and the production of an $\mathrm{MS}^{2}$ fragment ion at $m / z$ 301. Similarly, peak $5^{\mathrm{MT}}$ was identified as a kaempferol glycoside $\left(\lambda_{\max }\right.$ around $348 \mathrm{~nm}, \mathrm{MS}^{2}$ fragment at $\mathrm{m} / z$ 285). Tentative identities of these compounds were assigned based on their pseudomolecular ions using a similar reasoning to that for isorhamnetin derivatives. Thus, peaks $2^{\mathrm{MT}}\left([\mathrm{M}-\mathrm{H}]^{-}\right.$at $\left.m / z 771\right)$ and $5^{\mathrm{MT}}\left([\mathrm{M}-\mathrm{H}]^{-}\right.$ at $m / z 639$ ) could correspond to quercetin- $O$-deoxyhexoside- $O$ dihexoside and kaempferol-O-deoxyhexoside- $O$-dihexoside, respectively, whereas peak $7^{\mathrm{MT}}\left([\mathrm{M}-\mathrm{H}]^{-}\right.$at $m / z$ 755) was tentatively assigned as quercetin- $O$-hexoside- $O$-rutinoside.
Compound $8^{\mathbf{M T}}$ was positively identified as quercetin-3-Orutinoside according to its retention time, mass and UV-vis characteristics by comparison with a commercial standard.

The pills of milk thistle showed the presence of five (peaks $20^{\mathrm{MT}}, 21^{\mathrm{MT}}, 22^{\mathrm{MT}}, 23^{\mathrm{MT}}$ and $24^{\mathrm{MT}}$ ) flavonolignans (silymarin), assigned based on their UV spectra ( $\lambda_{\max }$ around $286-290 \mathrm{~nm}$ ), the observation of the ion at $m / z 481$ and a very characteristic fragmentation pattern observed in many studies. ${ }^{33-43}$ Nevertheless, due to the lack of commercial standards and difficulty in interpreting fragmentation, the complete identification of these compounds was not possible, and therefore they were characterized as silymarin derivatives. These compounds were quantified using a taxifolin calibration curve. Compound $24^{\mathrm{MT}}$ was identified as a hydroxylated silibinin taking into account its pseudomolecular ion, $16 \mathrm{u}$ higher than peaks $20^{\mathrm{MT}}-23^{\mathrm{MT}}$, and the findings of Venisetty et al. $^{44}$ Finally, peak $18^{\mathrm{MT}}(1,3-O-$ caffeolyquinic acid) was identified taking into account the retention time and fragmentation pattern observed for compound $11^{\mathrm{A}}$, and peak $19^{\mathrm{MT}}$ was positively identified as taxifolin according to its retention, mass and UV-vis characteristics by comparison with a commercial standard.

Isorhamnetin-O-deoxyhexoside- $O$-hexoside and isorhamnetin-O-rutinoside were the main phenolic compounds in milk thistle syrup, while hydroxyl silybin was the most prominent compound in the pills.

\subsection{Antimicrobial activity}

The screening of the antimicrobial activity of artichoke and milk thistle was performed using the different formulations (pills and syrups) and the results are presented in Table 5 . Among the artichoke-based samples, only the pills revealed antimicrobial activity, inhibiting the growth of MRSA with a MIC value of $1.9 \mathrm{mg} \mathrm{mL} \mathrm{m}^{-1}$. In contrast to the results obtained by Alves et al., ${ }^{45}$ where vanilic acid inhibited the growth of Escherichia coli and Proteus mirabilis, among others, the syrup of artichoke, which contained the referenced acid, did not inhibit the bacterial growth of the studied cultures, which might be due to its low concentration in the sample.

Regarding milk thistle, the syrup presented the highest antimicrobial activity, with lower MIC values, and proved to be able to inhibit the growth of Escherichia coli, ESBL producing Escherichia coli, MRSA and Pseudomonas aeruginosa, with MIC values ranging from 0.2 to $1.3 \mathrm{mg} \mathrm{mL}^{-1}$. The pills showed antimicrobial activity for Escherichia coli ESBL at $15 \mathrm{mg} \mathrm{mL}^{-1}$, but did not inhibit the growth of the remaining bacteria. Among

Table 5 Antimicrobial activity of pills and syrups of artichoke and milk thistle against bacterial clinical isolates (MIC values, $\mathrm{mg} \mathrm{mL}^{-1}$ )

\begin{tabular}{lccrrr}
\hline & \multicolumn{2}{l}{ Artichoke } & & \multicolumn{2}{l}{ Milk thistle } \\
\cline { 2 - 3 } Bacteria & Pills & Syrup & & Pills & Syrup \\
\hline Escherichia coli & $>15$ & $>100$ & & $>15$ & 0.3 \\
Escherichia coli ESBL & $>15$ & $>100$ & & 15 & 0.2 \\
Proteus mirabilis & $>15$ & $>100$ & & $>15$ & $>2.6$ \\
MRSA & 1.9 & $>100$ & & $>15$ & 0.2 \\
Pseudomonas aeruginosa & $>15$ & $>100$ & $>15$ & 1.3
\end{tabular}


the studied formulations of these plants, none of them was able to inhibit Proteus mirabilis at the studied concentrations.

As far as we know, there are no reports on the antimicrobial activity of pills or syrups containing artichoke or milk thistle, although there are studies performed with hydroalcoholic extracts of artichoke, which exhibited antimicrobial activity against Escherichia coli and Salmonella abony enterica. ${ }^{6}$ Moreover, Zhu et $a$ l. $^{46}$ performed a study using several fractions obtained from artichoke leaves, showing that at least six kinds of bacteria were sensitive to these extracts, including Bacillus subtilis, Staphylococcus aureus, Agrobacterium tumefaciens, Micrococcus luteus, Escherichia coli, and Salmonella typhimurium. On the other hand, ethanolic extracts from milk thistle seeds revealed antimicrobial activity in several clinical bacterial isolates, such as Escherichia coli, Staphylococcus aureus, Staphylococcus saprophyticus, and Klebsiella pneumoniae when mixed with agar media. ${ }^{8}$ Furthermore, several compounds isolated from artichoke also showed antimicrobial activity against microbial strains, including some of the bacteria used in the present study, namely Escherichia coli, Staphylococcus aureus, and Pseudomonas aeruginosa. ${ }^{46}$ One of the compounds isolated and tested by Zhu et al. ${ }^{46}$ that revealed antimicrobial activity was 3,5-O-dicaffeoylquinic acid, found in the pills of artichoke studied herein, which could explain its antimicrobial activity; the same observation can be made for luteolin and apigenin derivatives that were present in this formulation. $p$-Coumaric acid (detected in the pills and syrup of artichoke and in the syrup of milk thistle) was tested by Lou et $a l^{47}$ and revealed activity against Escherichia coli, Staphylococcus aureus, Salmonella typhimurium, and Shigella dysenteriae; nonetheless, in the present study not all of the formulations containing this molecule presented antimicrobial activity. On the other hand, CetinKaraca and Newman ${ }^{48}$ reported the antimicrobial capacity of 5-O-caffeoylquinic acid against Escherichia coli and several other microbial cultures, which might justify the activity of the syrup of milk thistle that contained this molecule. The antimicrobial capacity of the milk thistle pills could also be related to the presence of silibinin and silymarin, which revealed this kind of activity in a study performed with Escherichia coli, Staphylococcus aureus, and Pseudomonas aeruginosa. ${ }^{9}$

Overall, the studied formulations were found to be a good source of phenolic compounds. Milk thistle syrup presented the highest variety of these phytochemicals with sixteen different compounds identified and the highest concentration of flavonoids, which could possibly explain its potent antimicrobial activity. Nonetheless, the remaining formulations were also able to inhibit some of the studied bacterial strains and also proved to be rich in phenolic compounds, among which artichoke pills showed the highest concentration of phenolic acids.

\section{Acknowledgements}

The authors are grateful to the Foundation for Science and Technology (FCT, Portugal) and FEDER under the Programe PT2020 for financial support to CIMO (UID/AGR/00690/2013) and LSRE (Project UID/EQU/50020/2013), and for a grant to L. Barros (SFRH/BPD/107855/2015).

\section{References}

1 WHO, The top 10 causes of death, 2004, http://www.who.int/ mediacentre/factsheets/fs310/en/.

2 F. K. Touani, A. J. Seukep, D. E. Djeussi, A. G. Fankam, J. A. K. Noumedem and V. Kuete, BMC Complementary Altern. Med., 2014, 14, 258-265.

3 J.-E. Li, S.-T. Fan, Z.-H. Qiu, C. Li and S.-P. Nie, LWT - Food Sci. Technol., 2015, 64, 1022-1027.

4 M. Häusler, M. Ganzera, G. Abel, M. Popp and H. Stuppner, Chromatographia, 2002, 56, 407-411.

5 C. Pereira, L. Barros, A. M. Carvalho, C. Santos-Buelga and I. C. F. R. Ferreira, Food Funct., 2015, 6, 56-62.

6 D. Ionescu, G. Predan, G. D. Rizea, D. Mihele, A. Dune, G. Ivopol and C. Ionita, Bull. Transilv. Univ. Brasov, Ser. II For. Wood Ind. Agric. Food Eng., 2013, 6, 113-120.

7 A. A. Gaafar and Z. A. Salama, J. Biol. Agric. Healthcare, 2013, 3, 1-6.

8 I. J. Abed, R. Al-moula and G. A. Abdulhasan, World J. Exp. Biosci., 2015, 3, 36-39.

9 D. R. de Oliveira, S. R. Tintino, M. F. B. M. Braga, A. A. Boligon, M. L. Athayde, H. D. M. Coutinho, I. R. A. de Menezes and R. Fachinetto, BioMed Res. Int., 2015, 2015.

10 K. Radimer, B. Bindewald, J. Hughes, B. Ervin, C. Swanson and M. F. Picciano, Am. J. Epidemiol., 2004, 160, 339-349.

11 C. Pereira, R. C. Calhelha, L. Barros, M. J. R. P. Queiroz and I. C. F. R. Ferreira, Ind. Crops Prod., 2014, 52, 709-713.

12 C. Pereira, R. C. Calhelha, L. Barros and I. C. F. R. Ferreira, Ind. Crops Prod., 2013, 49, 61-65.

13 EUCAST: European Committee on Antimicrobial Susceptibility Testing, 2013, ESCMID: European Society of Clinical Microbiology and Infectious Diseases.

14 Performance Standards for Antimicrobial Susceptibilitty Testing; 2008, CLSI document M100-S18; Clinical and Laboratory Standards Institute: Wayne, PA, USA.

15 Comité de L’Antibiogramme De La Société Française de Microbiologie, Communiqué, 2012, Société Française de Microbiologie: Paris, France.

16 M. J. Alves, I. C. F. R. Ferreira, A. Martins and M. Pintado, J. Appl. Microbiol., 2012, 113, 466-475.

17 M. N. Clifford, S. Knight and N. Kuhnert, J. Agric. Food Chem., 2005, 53, 3821-3832.

18 M. N. Clifford, K. L. Johnston, S. Knight and N. Kuhnert, J. Agric. Food Chem., 2003, 51, 2900-2911.

19 M. I. Dias, L. Barros, M. Dueñas, E. Pereira, A. M. Carvalho, R. C. Alves, M. B. P. P. Oliveira, C. Santos-Buelga and I. C. F. R. Ferreira, Food Chem., 2013, 141, 4152-4160.

20 R. Guimarães, L. Barros, M. Dueñas, R. C. Calhelha, A. M. Carvalho, C. Santos-Buelga, M. J. R. P. Queiroz and I. C. F. R. Ferreira, Food Chem., 2013, 136, 718-725.

21 A. H. P. Souza, R. C. G. Corrêa, L. Barros, R. C. Calhelha, C. Santos-Buelga, R. M. Peralta, A. Bracht, M. Matsushita 
and I. C. F. R. Ferreira, Food Res. Int., 2015, 78, 286294.

22 F. Sánchez-Rabaneda, O. Jáuregui, R. M. Lamuela-Raventós, J. Bastida, F. Viladomat and C. Codina, J. Chromatogr., A, 2003, 1008, 57-72.

23 K. Schütz, D. Kammerer, R. Carle and A. Schieber, J. Agric. Food Chem., 2004, 52, 4090-4096.

24 R. Ferracane, N. Pellegrini, A. Visconti, G. Graziani, E. Chiavaro, C. Miglio and V. Fogliano, J. Agric. Food Chem., 2008, 56, 8601-8608.

25 S. Lombardo, G. Pandino, G. Mauromicale, M. Knödler, R. Carle and A. Schieber, Food Chem., 2010, 119, 11751181.

26 G. Pandino, S. Lombardo, G. Mauromicale and G. Williamson, Food Chem., 2011, 126, 417-422.

27 G. Pandino, S. Lombardo, G. Mauromicale and G. Williamson, J. Food Compos. Anal., 2011, 24, 148-153.

28 S. C. Gouveia and P. C. Castilho, Food Res. Int., 2012, 48, 712-724.

29 I. M. Abu-Reidah, D. Arraez-Roman, A. Segura-Carretero and A. Fernandez-Gutierrez, Food Chem., 2013, 141, 22692277.

30 M. A. Farag, S. H. El-Ahmady, F. S. Elian and L. A. Wessjohann, Phytochemistry, 2013, 95, 177-187.

31 J. Wu, Y. Qian, P. Mao, L. Chen, Y. Lu and H. Wang, J. Chromatogr. B: Anal. Technol. Biomed. Life Sci., 2013, 927, 173180.

32 M. Wang, J. E. Simon, I. F. Aviles, K. He, Q. Y. Zheng and Y. Tadmor, J. Agric. Food Chem., 2003, 51, 601-608.

33 A. R. Bilia, M. C. Bergonzi, S. Gallori, G. Mazzi and F. F. Vincieri, J. Pharm. Biomed. Anal., 2002, 30, 613624.
34 A. R. Bilia, D. Salvini, G. Mazzi and F. F. Vincieri, Chromatographia, 2001, 53, 210-215.

35 Y. Zhao, B. Chen and S. Yao, J. Pharm. Biomed. Anal., 2005, 38, 564-570.

36 S. Kéki, K. Tóth, M. Zsuga, R. Ferenczi and S. Antus, Rapid Commun. Mass Spectrom., 2007, 21, 2255-2262.

37 J. I. Lee, B. H. Hsu, D. Wu and J. S. Barrett, J. Chromatogr., A, 2006, 1116, 57-68.

38 J. I. Lee, M. Narayan and J. S. Barrett, J. Chromatogr. B: Anal. Technol. Biomed. Life Sci., 2007, 845, 95-103.

39 X.-L. Cai, D.-N. Li, J.-Q. Qiao, H.-Z. Lian and S.-K. Wang, Asian J. Chem., 2009, 21, 63-74.

40 K. Wang, H. Zhang, L. Shen, Q. Du and J. Li, J. Pharm. Biomed. Anal., 2010, 53, 1053-1057.

41 B. J. Brinda, H. J. Zhu and J. S. Markowitz, J. Chromatogr. B: Anal. Technol. Biomed. Life Sci., 2012, 902, 1-9.

42 L. Calani, F. Brighenti, R. Bruni and D. Del Rio, Phytomedicine, 2012, 20, 40-46.

43 H. S. Althagafy, T. N. Graf, A. A. Sy-Cordero, B. T. Gufford, M. F. Paine, J. Wagoner, S. J. Polyak, M. P. Croatt and N. H. Oberlies, Bioorg. Med. Chem., 2013, 21, 3919-3926.

44 R. K. Venisetty, S. Keshetty and V. Ciddi, Indian J. Pharm. Educ. Res., 2011, 45, 384-391.

45 M. J. Alves, I. C. F. R. Ferreira, H. J. C. Froufe, R. M. V. Abreu, A. Martins and M. Pintado, J. Appl. Microbiol., 2013, 115, 346-357.

46 X. Zhu, H. Zhang and R. Lo, J Agric Food Chem, 2004, 52, 7272-7278.

47 Z. Lou, H. Wang, S. Rao, J. Sun, C. Ma and J. Li, Food Control, 2012, 25, 550-554.

48 H. Cetin-Karaca and M. C. Newman, Food Biosci., 2015, 11, 8-15. 